\title{
Formulation and Evaluation of Floating Drug Delivery System for Oxcarbazepine
}

\author{
Gunasekar Manoharan ${ }^{1 *}$, Balaji Nagarajan ${ }^{1}$ and Bhargava Gottam ${ }^{2}$ \\ ${ }^{1}$ New Jersey Bioscience Centre, New Jersey, USA \\ ${ }^{2}$ Harrisburg University of Science and Technology, Pennsylvania, USA \\ *Corresponding Author: Gunasekar Manoharan, New Jersey Bioscience Centre, \\ New Jersey, USA.
}

Received: December 10, 2021

Published: December 27, 2021

(C) All rights are reserved by Gunasekar

Manoharan., et al.

\begin{abstract}
Sustained release tablets of oxcarbazepine that float, erode and diffuse were prepared using various hydrophilic polymers. The buoyancy of the tablets was achieved by incorporation of the gas-generating agent sodium bicarbonate. The effect of various parameters on buoyancy and release profile was investigated. The tablets became buoyant within minutes and floated for more than 12 hours in vitro with good integrity and released more than $90 \%$ of the drug. The tablets exhibited prolonged floating properties due to low density polymers and formation of $\mathrm{CO}_{2}$ by a gas generating material. A zero-order drug release involving swelling and erosion of the system was observed. This study shows that tablet composition and mechanical strength have the greatest influence on the floating properties and sustained drug release. The system was shown to have an excellent floating ability and sustained release characteristics in vitro, irrespective of $\mathrm{pH}$. The floating dosage form was found to be a feasible approach in delivering oxcarbazepine to the upper GIT to maximize drug absorption.
\end{abstract}

Keywords: Oxcarbazepine; Floating Tablets; HPMC K 4M; HPMC K 15M

\section{Introduction}

Oxcarbazepine, a keto analogue of carbamazepine has been reported to effectively treat partial and generalized tonic-clonic seizures. Oxcarbazepine is quickly and almost completely absorbed. Oxcarbazepine has a half-life of $2 \mathrm{hrs}$ [1,2]. Peak serum concentrations of the drug are reached in 3-8 hrs and steady state levels are achieved in about 3 days [3].

The recommended dosage of oxcarbazepine in adult patients with epilepsy is 600-1200 mg/day in 3 divided doses, which presents compliance problem for long term therapy [4]. A sustained release preparation that can remain in the stomach for a long time, adjusting with the narrow therapeutic window of the drug, thereby increasing the absorption of the drug, would cause lesser side effects and improve patient compliance $[5,6]$.

The convenience and ease of administration makes oral route the most popular and successful for controlled delivery of drugs.
Oral route offers greater flexibility in dosage form design, ease of production and low cost. Gastro intestinal tract is the first destination in case of oral drug delivery system. In recent years, per oral dosage forms for gastric retention have drawn more and more attention for their theoretical advantage in permitting control over time and site of drug release [7]. This would be particularly valuable for drugs that exhibit an absorption window in the upper part of the stomach or pylorus $[7,8]$.

Today, a wide range of gastrointestinal controlled delivery system is available in the market. To increase the gastric residence time, systems like swelling and expanding systems, floating systems and bio adhesive systems have been developed in the last two decades.

Floating units, well known as hydrodynamically balanced system (HBS), has been discussed in several publications and patents; an extensive review was written by [4]. Floating based on low den- 
sity polymers [9,10], empty globular shells [11], multilayered polymer films [12], polycarbonate spheres [13] gel-type matrix [14] foaming microcapsules [15] foaming polystyrenes [16], $\mathrm{CO}_{2}$ generation [17], low-density dry solid systems [18], sodium alginate beads [19] have been developed.

In the present study, floating tablets with density $<1$ were prepared using different polymers. The effect of hardness, $\mathrm{pH}$, stirring speed, storage, polymer and effervescent agent concentration on buoyancy and release profile was investigated.

\section{Materials and Methods}

\section{Materials}

Oxcarbazepine was obtained as a gift sample from Zydus Healthcare Ltd, India. Hydroxy propyl methyl cellulose (HPMC K 4M and HPMC K 15M, Sun Pharmaceuticals, India), Carbopol 934 $\mathrm{P}$ and Eudragit RL (Torrent Pharmaceuticals, India), Cross Carboxy Methyl Cellulose (Cross CMC, Genuine Chemicals, India), Sodium Lauryl Sulphate (SLS, Nice Chemicals, India). A multi- punch machine (Cadmach, India) and UV-VIS spectrophotometer (UV-1601, Shimadzu, Japan) were used. All other materials were of pharmaceutical or analytical grade.

\section{Preparation of floating tablets}

Floating tablets were prepared by both wet granulation and direct compression method. In the wet granulation method, granules were prepared using absolute ethanol as granulating agent. Lubricants and glidants were added one after to the granules and mixed each time by tumbling process in a dry bottle. Accurately weighed amount of granules (containing $240 \mathrm{mg}$ of drug and polymers) were placed on the die cavity and a preparatory pressing was made. Thereafter, second component that contained a loading dose (60 mg of drug and $20 \mathrm{mg}$ of pre-gelatinized starch) as a powder mixture was added and the final tablets were compressed with a suitable compression force such that the tablet hardness was 2,4 and $8 \mathrm{~kg} / \mathrm{cm}^{2}$.

In the direct compression method, the powders after passing through appropriate sieves were mixed and compressed directly in a similar method mentioned above. The amount of polymers was optimized to obtain formulations that would afford $90 \%$ release of the drug in $12 \mathrm{hrs}$. The formulae for different trial formulations are given table 1 .

\begin{tabular}{|l|c|c|c|c|c|}
\hline Ingredients & $\begin{array}{c}\text { F1 } \\
\text { (mg) }\end{array}$ & $\begin{array}{c}\text { F2 } \\
\text { (mg) }\end{array}$ & $\begin{array}{c}\text { F3 } \\
\text { (mg) }\end{array}$ & $\begin{array}{c}\text { F4 } \\
\text { (mg) }\end{array}$ & $\begin{array}{c}\text { F5 } \\
\text { (mg) }\end{array}$ \\
\hline Oxcarbazepine & 300 & 300 & 300 & 300 & 300 \\
HPMC K4M & 75 & 40 & 25 & 25 & 40 \\
HPMC K15M & - & - & 50 & - & - \\
Carbopol 934 P & - & - & - & 50 & - \\
Cross CMC & - & - & - & - & 35 \\
Eudragit RL & - & 35 & - & - & - \\
Sodium bicarbonate & 75 & 75 & 75 & 75 & 75 \\
Calcium carbonate & 10 & 10 & 10 & 10 & 10 \\
Pre-gelatinized & 20 & 20 & 20 & 20 & 20 \\
starch & 15 & 15 & 15 & 15 & 15 \\
Magnesium stearate & 5 & 5 & 5 & 5 & 5 \\
Talc & & & & & \\
\hline
\end{tabular}

Table 1: Formulae of different trail formulations.

\section{Dissolution study}

USP XXII dissolution test II was used to study drug release. Artificial gastric juice $900 \mathrm{ml}(\mathrm{pH}$ 1.2. $0.1 \mathrm{~N} \mathrm{HCl}$ and 1\% SLS) was used as the dissolution medium. The paddle stirrer was lowered so that the lower end of the stirrer was $25 \mathrm{~mm}$ above from the base of the flask. The temperature was maintained at $37^{\circ} \mathrm{C} \pm 1^{\circ} \mathrm{C}$ with a stirring speed of $75 \mathrm{rpm}$. Aliquots $(5 \mathrm{ml})$ were withdrawn at predetermined time intervals and replaced by an equivalent volume of fresh solvent. The amount of drug dissolved was measured spectrophotometrically at $255 \mathrm{~nm}$.

\section{Buoyancy test}

Tablets were placed in a $400 \mathrm{ml}$ flask containing $0.1 \mathrm{~N} \mathrm{HCl}(\mathrm{pH}$ 1.2) maintained at $37^{\circ} \mathrm{C}$. The time needed for the tablets to become afloat, and the floating duration were determined.

\section{Results and Discussion}

Tablets with hardness of 2 and $4 \mathrm{~kg} / \mathrm{cm}^{2}$ prepared by direct compression showed poor floating and sustained release properties. Tablets started to float slowly, but disintegrated completely within 5 minutes. Fragments of the tablets were floating up to 6 hrs. Tablets with hardness of $8 \mathrm{~kg} / \mathrm{cm}^{2}$ floated after 30 minutes and disintegrated within two hours. The powder mixture was free flowing, non-segregating and compressible mixture, but it was found that direct compression was not suitable for preparing floating tablets of oxcarbazepine. As shown in table 2, tablet formulations prepared by wet granulation method with a hardness of $4 \mathrm{~kg} / \mathrm{cm}^{2}$ showed good floating properties and sustained release up to 12 
hours. Tablet formulations with $2 \mathrm{~kg} / \mathrm{cm}^{2}$ eroded quickly whereas tablet formulations with $8 \mathrm{~kg} / \mathrm{cm}^{2}$ sustained the drug release for 24 hours and floated for more than 24 hours. Further tablet formulations prepared by wet granulation method with a hardness of 4 $\mathrm{kg} / \mathrm{cm}^{2}$ were taken for all further studies since they showed good floating and release properties.

\begin{tabular}{|l|c|c|c|}
\hline Formulation & $\begin{array}{c}\text { Buoyancy } \\
\text { time (mins) }\end{array}$ & $\begin{array}{c}\text { Floating } \\
\text { duration } \\
\text { (hrs) }\end{array}$ & Matrix integrity \\
\hline F1 & 1 & 16 & $\begin{array}{c}\text { Very good, eroded } \\
\text { very slowly }\end{array}$ \\
F2 & 8 & 12 & $\begin{array}{c}\text { Average, eroded } \\
\text { quickly } \\
\text { F3 }\end{array}$ \\
F4 & 1 & 16 & $\begin{array}{c}\text { Very good, eroded } \\
\text { very slowly } \\
\text { F5 }\end{array}$ \\
\hline
\end{tabular}

Table 2: Buoyancy time, floating time, and matrix integrity of tablet formulations prepared by wet granulation.

\section{Dissolution study}

Oxcarbazepine was insoluble in water and poorly soluble in organic solvents. To increase the solubility of the drug, 1\% SLS was added to the dissolution media as per the FDA guidelines. The release achieved was better and consistent. Tablet formulations showed a release up to $90 \%$ at the end of the study period of 12 hours.

The cumulative percent drug release for the tablets prepared increased in the order of formulation $\mathrm{F} 5>\mathrm{F} 2>\mathrm{F} 4>\mathrm{F} 3>\mathrm{F} 1$. Once the tablet came in contact with the dissolution medium, the loading dose $(60 \mathrm{mg})$ was released rapidly. Because the gas generated is trapped in and protected by the gel formed by the hydration of HPMC, successful floating properties were seen in all tablet formulations. Formulations F5 and F2 were found to erode quickly, and release rate of the drug was higher when compared to other formulations. Cross CMC did not contribute much to the floating and sustained release properties.

In F2, since Eudragit RL is more hydrophilic, hydrated faster and eroded quickly. In F4 the presence of carbopol with HPMC controlled the swelling rate and the tablets eroded slowly. It is report- ed that, provided that the tablet remains buoyant on the gastric fluid, the presence of carbopol could possibly aid in retaining the tablet, on oral ingestion, within the stomach by assisting in the adhesion of the dosage form on the gastric wall, which may add ease in enhancing the tablet gastric residence time. Moreover, incorporation of carbopol within the formulation may assist in the protection of the drug from being attacked by food components when the dosage form is co administered with food by minimizing drug-food contact, which in turn could possibly result in enhancement of the drug bioavailability.

In formulations F1 and F3 where HPMC K4M and HPMC K15M are used, a great and stable persistent buoyancy was obtained. The generated buoyancy was great such that, the tablets floated within 1 minute. The formulations had good matrix integrity with less swelling and sustained the release of the drug up to 14 hours.

Data of the in vitro release were fitted to different equations and kinetic models to explain the release kinetics of oxcarbazepine from these floating tablet formulations. All the profiles fitted with a zero-order equation or Korsemeyer model. It was considered that oxcarbazepine was released from the tablet formulation by diffusion with zero order kinetics. Since formulations FI and F3 showed good floating and sustained release characteristics when compared to other formulations, they were selected to study the effects of various parameters on floating and drug release properties. The dissolution profiles of the formulations are shown in figure 1.

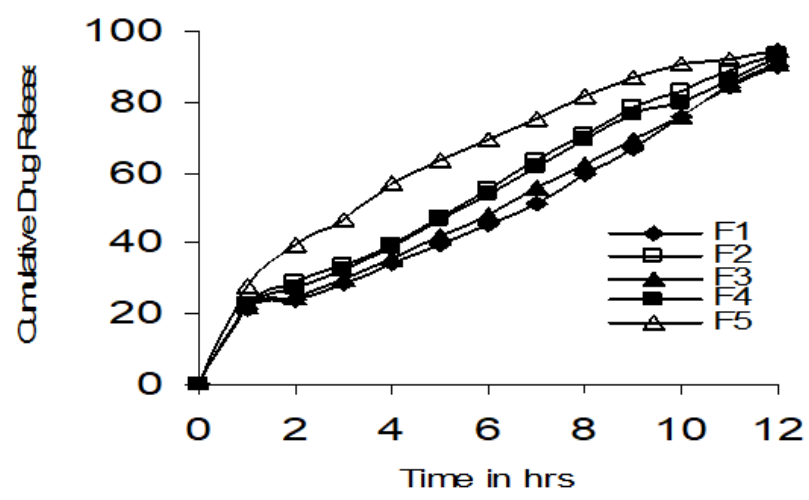

Figure 1: Dissolution profile of various floating tablet formulations (Each data point is the mean of three determinations). 
Effect of various parameters on drug release and floating time

\section{Effect of stirring speed}

The effect of stirring speed on the dissolution profiles (Figure 2) was studied at stirring rates of 50 and $100 \mathrm{rpm}$ for F1 and F3. The tablets of both formulations floated within 45 seconds at $100 \mathrm{rpm}$. It was observed that increasing the rate of agitation had a very small difference for drug release and floating time at two different rotating speeds, because of higher concentrations of HPMC in these formulations. This in turn can be explained by the fact that the amount of HPMC was the key factor determining the in vitro drug release.

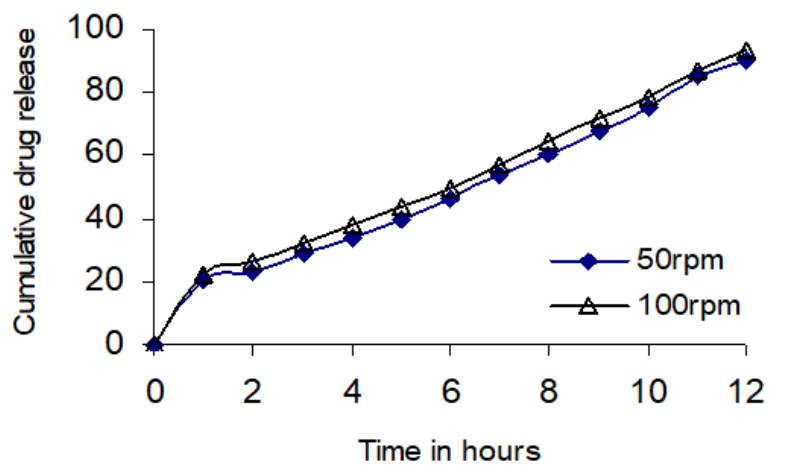

Figure 2a: Effect of stirring speed on dissolution profile of F1 (Each data point is the mean of three determinations).

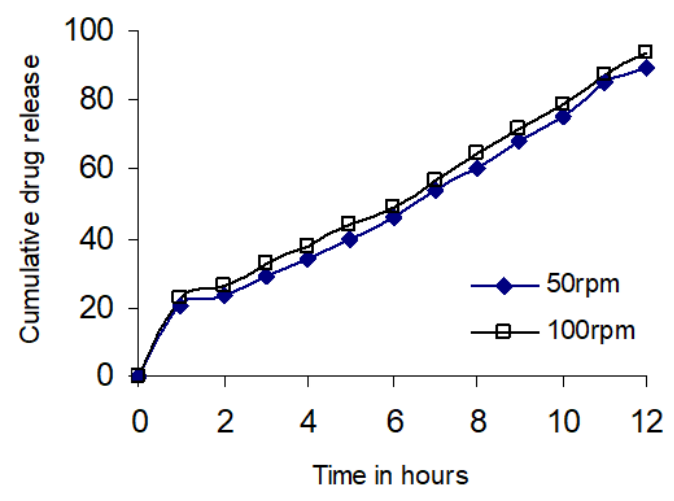

Figure 2b: Effect of stirring speed on dissolution profile of F3

(Each data point is the mean of three determinations).

\section{Effect of hardness}

The effect of hardness on dissolution profiles of the formulations F1 and F3 are shown in Figure 3a. It was observed that the time taken by the tablets to become afloat increased as the hardness increased. Tablet formulations with hardness $2 \mathrm{~kg} / \mathrm{cm}^{2}$ floated in less than 30 seconds (Figure 3b). Tablets with hardness $8 \mathrm{~kg} /$ $\mathrm{cm}^{2}$ took nearly 3 minutes to become afloat and remained floating for nearly 17 hours releasing 85\% of the drug. A lower hardness resulted in tablets with a higher porosity, which facilitated the water penetration and therefore the effervescent reaction. In addition, the initial density of the softer tablets was lower. A difference in tablet hardness reflects difference in tablet density and porosity, which are supposed to result in different release patterns of the drug by affecting the rate of penetration of the dissolution fluid at the surface of the tablet and formation of the gel barrier. Therefore, such an effect is expected to be prominent during the initial phase of the dissolution curve. Results showed that tablet hardness had little effect on the release profile. This can be attributed to the fact that variation in the release pattern as a result of differences in tablet density and porosity during the initial phase of dissolution could possibly be diminished by the high affinity of the polymer (HPMC) to the aqueous solution.

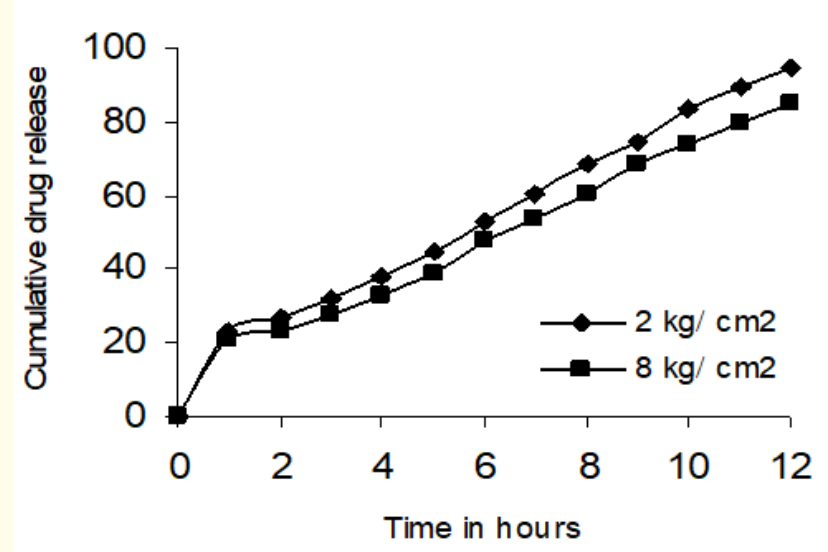

Figure 3a: Effect of hardness on dissolution profile of F1 (Each data point is the mean of three determinations). 


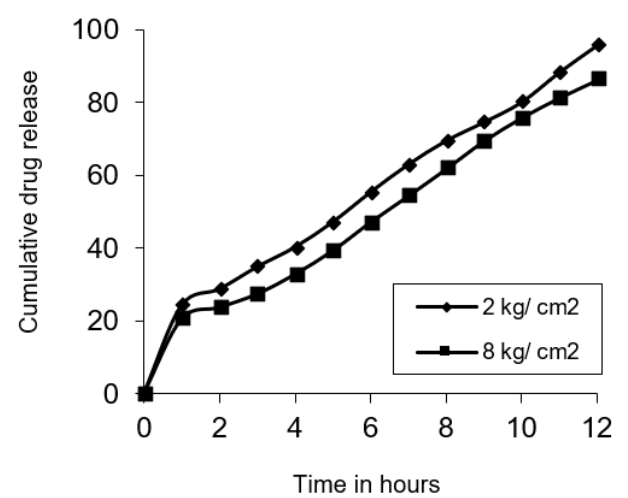

Figure 3b: Effect of hardness on dissolution profile of F3 (Each data point is the mean of three determinations).

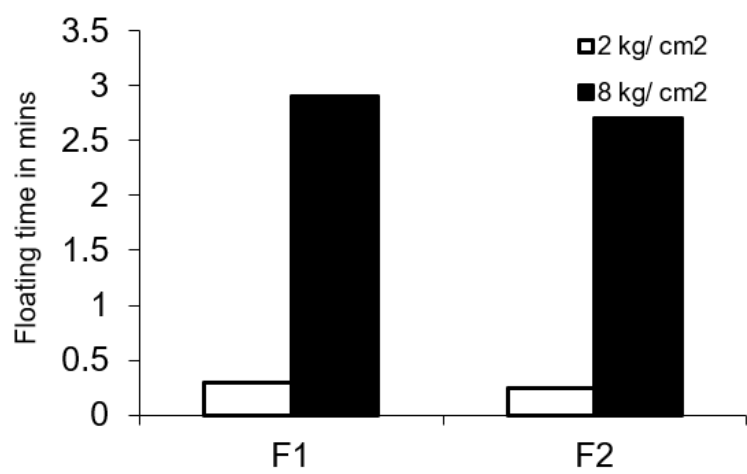

Figure 3c: Effect of hardness on floating time (Each data point is the mean of three determinations).

\section{Effect of storage time}

The effect of storage time on buoyancy time (Figure 4) and drug release for tablet formulations was studied after placing the tablets under accelerated stability condition for 90 days. For a time interval of 15 days, one tablet was taken from each formulation and the buoyancy time was determined as per the procedure.

The buoyancy time of the tablet formulations decreased when stored under accelerated stability conditions. This can be due to the presence of moisture in the surrounding, which might have lead to the formation of $\mathrm{CO}_{2}$ inside the formulation that would help the tablet float instantly. There was no significant change in the release rate of the drug in all the formulations. Moisture uptake test was performed for the tablet formulations and the increase in weight for all formulations was not more than $3 \%$.

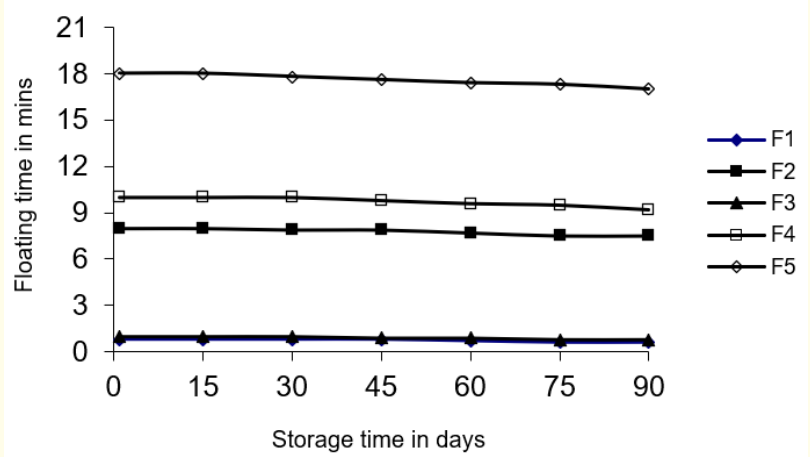

Figure 4: Effect of storage on buoyancy time (Each data point is the mean of three determinations).

\section{Effect of effervescent agents}

Tablet formulations floated for longer time periods due to the presence of adequate quantities of gas generating materials, whose $\mathrm{CO}_{2}$ evolution was entrapped in the gel network formed by the hydrophilic polymers, thereby reducing the density of the tablet. Increasing the concentration of sodium bicarbonate from $25 \% \mathrm{w} / \mathrm{w}$ to $40 \% \mathrm{w} / \mathrm{w}$ in F1and F3 resulted in tablets that floated immediately within seconds, because of a faster and higher $\mathrm{CO}_{2}$ generation. The release rate of the drug was increased due to the formation of large pores and faster erosion of the tablets and further the matrix integrity was lost.

Reducing the concentration of sodium bicarbonate from $25 \% \mathrm{w} / \mathrm{w}$ to $10 \% \mathrm{w} / \mathrm{w}$, decreased the drug release rate (Figure $5 \mathrm{a}$ ) and increased the floating time (Figure $5 b$ ). In finding the optimal amount (75 mg) of sodium bicarbonate in tablet formulations gave good sustained release profile and buoyancy properties.

It is worth mentioning here that carbonates apart from imparting buoyancy to the dosage form also provides initial alkaline microenvironment for polymers to form gel. It was found that magnesium stearate improved the buoyancy property of the tablet formulations. The beneficial effect of magnesium stearate on the buoyancy properties of the tablets is probably due to the hydrophobic nature of the compound. Water uptake and penetration through 
the delivery system are significantly slowed down by the addition of magnesium stearate, thus improving the buoyancy property.

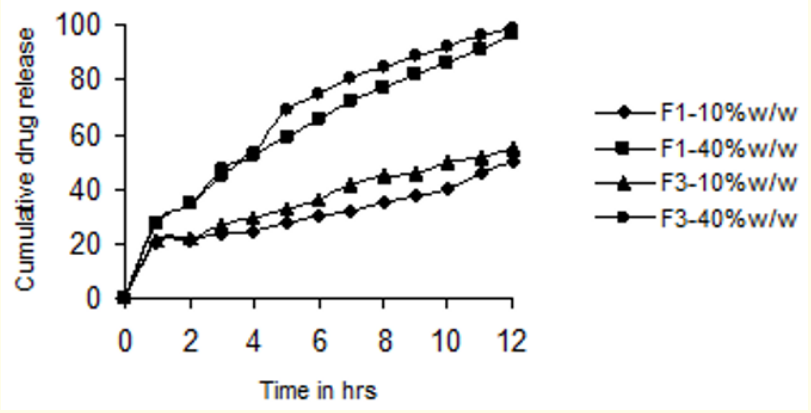

Figure 5a: Effect of effervescent agent on dissolution profiles (Each data point is the mean of three determinations).

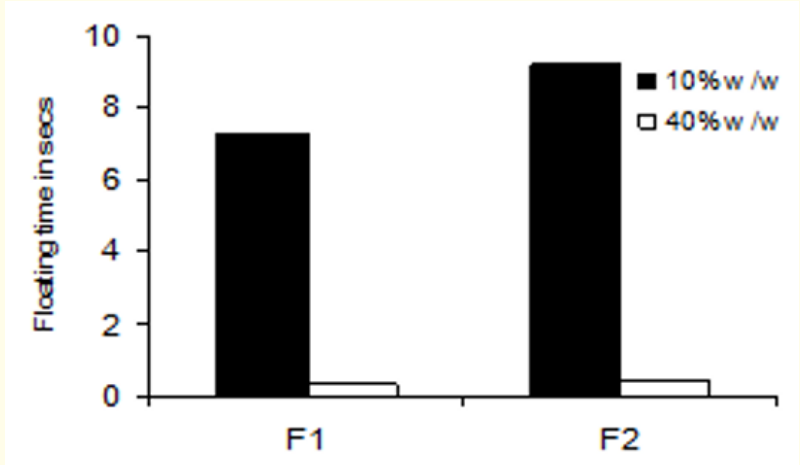

Figure 5b: Effect of effervescent agent on floating time (Each data point is the mean of three determinations).

\section{Effect of HPMC concentration}

The effect of HPMC concentration on drug release was studied extensively for F1 (Figure 6). HPMC formed a stable hydrogel layer upon contact with the dissolution medium. The hydrogel layer therefore formed was strong enough and could inhibit further water penetration into the tablet and entrapped the generated $\mathrm{CO}_{2}$ maintaining the floating capacity of the dosage form.

Increasing the HPMC concentration above $25 \% \mathrm{w} / \mathrm{w}$ decreased the drug release to a great extent, i.e. releasing the drug for more than $16 \mathrm{hrs}$. Tablet erosion was very slow and the matrix integrity was maintained. In contrast, the drug release was at a faster rate at below $25 \% \mathrm{w} / \mathrm{w}$ concentration. There was no significant change in floating time due to change in HPMC concentration.
It has been reported that higher molecular weight polymers with slower rates of polymer hydration are usually followed by enhanced floating behavior. The same phenomenon has been observed in the current study. It was seen that HPMC played a major role in the tablet formulations on buoyancy properties and drug release.

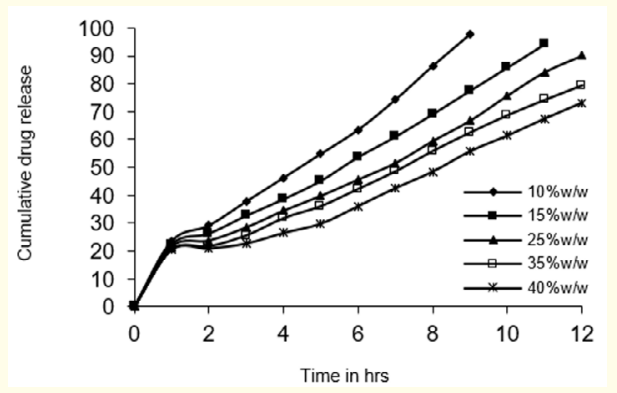

Figure 6: Effect of HPMC K4M on dissolution profiles (Each data point is the mean of three determinations).

\section{Effect of pH}

One important problem with any sustained release formulation is the fact that many drug release rate depend upon the $\mathrm{pH}$ of the environment. In order to understand the influence of stomach $\mathrm{pH}$ after a meal on the sustained release of tablets, the dissolution test for F1was carried out at $\mathrm{pH} 2,4$ and 6 (Figure 7). It is well known that the release of a drug from a dosage form at a certain $\mathrm{pH}$ depends on the drug solubility and type of polymer used.

Across the range of $\mathrm{pH}$ values studied, the release of oxcarbazepine decreased, as there was an increase in pH. A smaller level of matrix disruption and drug solubility was observed. Tablets floated over 12 hours irrespective of the $\mathrm{pH}$ of the medium.

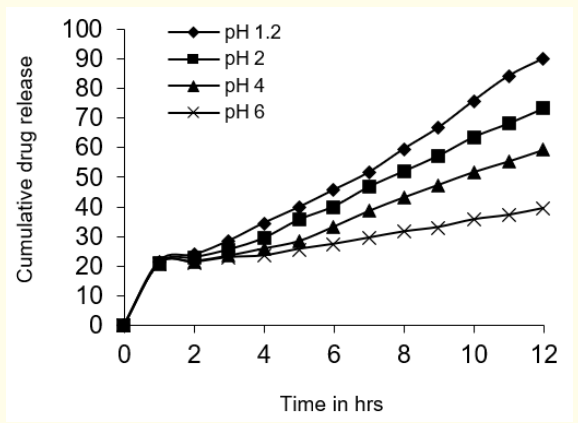

Figure 7: Effect of $\mathrm{pH}$ on dissolution profiles (Each data point is the mean of three determinations). 


\section{Conclusion}

These preliminary studies proved that HPMC played a major role in the tablet formulations on buoyancy properties and drug release. The floating dosage form entirely depends upon the choice of the polymer and effervescent agents. In conclusion, the new oral sustained release system in vitro showed good characteristics in relation to two parameters: controlled release of the drug and buoyancy in an acid medium. However, more studies will be necessary to probe the availability of the system In-vivo.

\section{Disclosure of Conflict of Interest}

Authors has declared that no competing interests exist.

\section{Bibliography}

1. Goodman and Gillman-Drugs effective in the treatment of the epilepsies in the pharmacological basis of therapeutics. Mc Graw Hill, New York.

2. Deshpande A., et al. "Controlled-release drug delivery systems for prolonged gastric residence: an overview". Drug Development and Industrial Pharmacy 22.6 (1996): 531-539.

3. Deshpande A., et al. "Development of a novel controlled-release system for gastric retention". Pharmaceutical Research 14.6 (1997): 815-819.

4. Buri P., et al. "Formes pharmaceutiques nouvelles, Technique et Documentation". Lavoisier (1985): 201-212.

5. Sheth P., et al. "The hydrodynamically balanced system (HB$\left.\mathrm{S}^{\mathrm{TM}}\right)$ : A novel drug delivery system for oral use". Drug Development and Industrial Pharmacy 10.2 (1984): 313-339.

6. Watanabe S., et al. "Solid therapeutic preparation remaining in stomach". U.S. Patent 3976764 (1976).

7. Mitra S B. "Polymers as biomaterials (Shalaby S. W., Hoffman A. S., Ratner B.D., Horbett T. A., eds)”. (1984): 293.

8. Thanoo. B. C., et al. "Oral sustained-release drug delivery systems using polycarbonate microspheres capable of floating on the gastric fluid". Journal of Pharmacy and Pharmacology 45 (1993): 21-24.

9. Bolton S., et al. "Floating sustained release therapeutic compositions". U.S. Patent 4814179, (1989).

10. Ichikawa M., et al. "A new multiple-unit oral floating system I: Preparation and in vitro evaluation of floating and sustainedrelease characteristics". Journal of Pharmaceutical Sciences 80 (1991): 1062-1066.
11. Ichikawa M., et al. "Granule remaining in stomach". US Patent 4,844,905, (1989).

12. Nakamichi K., et al. "Gastric remaining preparation, swollen molding, and production process”. EP 0717 988, 26 (1996).

13. Choi B Y., et al. "Preparation of alginate beads for floating drug delivery system: effects of carbon dioxide forming agents". International Journal of Pharmaceutics 239 (2002): 81-91.

14. Nur AO., et al. "Captopril floating and/or bioadhesive tablets: Design and release kinetics". Drug Development and Industrial Pharmacy 26.9 (2000): 965-969.

15. Nei Z., et al. "Design and evaluation of a two-layer floating tablet for gastric retention using cisapride as a model drug". Drug Development and Industrial Pharmacy 27.5 (2001): 469-474.

16. Hilton A K., et al. "Invitro and In-vivo evaluation of an oral sustained-release floating dosage form of amoxycillin trihydrate". International Journal of Pharmaceutics 86 (1992): 79-88.

17. Sas A., et al. "Optimization of floating matrix tablets and evaluation of their gastric residence time". International Journal of Pharmaceutics 195 (2000): 125-135.

18. Rouge N., et al. "Buoyancy and drug release patterns of floating minitablets containing Piretanide and Atenolol as model drugs". Pharmaceutical Development and Technology 3 (1998): 73-84.

19. Timmermans J., et al. "How well do floating dosage forms float". International Journal of Pharmaceutics 62 (1990): 207216.

\section{Assets from publication with us}

- Prompt Acknowledgement after receiving the article

- Thorough Double blinded peer review

- Rapid Publication

- Issue of Publication Certificate

- High visibility of your Published work

Website: www.actascientific.com/

Submit Article: www.actascientific.com/submission.php

Email us: editor@actascientific.com

Contact us: +919182824667 